Doktorand na Odeljenju za etnologiju i antropologiju, Filozofski fakultet, Univerzitet u Beogradu igorvujcicmusic@gmail.com

\title{
Digitalna nostalgija: vaporwave kao multimedijalna muzička fikcija ${ }^{1}$
}

\begin{abstract}
Apstrakt: Vaporwave kao muzički žanr s ograničenim brojem uglavnom anonimnih izvođača, ali i veoma ograničenim trajanjem od samo nekoliko godina, neodvojivo je povezan sa fenomenom interneta koji funkcioniše ne samo kao prostor u kome se susreću muzičari i njihova publika, već i kao primarni kulturni okvir ovog žanra. Oslanjajući se na tehnike obrade već postojećih muzičkih izraza, kao i na vizualne predstave i reference na popularnu kulturu devedesetih godina prošlog veka, označene u kontekstu žanra kao ,estetika”, vaporwave teži da iskaže i probudi kod svojih slušalaca nostalgiju za vremenom ranih početaka interneta, oblikujući svoj izraz, kako muzički tako i vizualni, sa ciljem da deluje ,kao da” dolazi iz drugog vremena. Fenomen vaporwave-a razmatraće se kroz nekoliko centralnih i međusobno povezanih pitanja - na koji način se tehnike obrade zvuka, vizualne predstave i elementi popularne kulture dovode u međusobnu vezu u okviru muzičkog žanra doprinoseći njegovoj multimedijalnoj prirodi, kako se ovi elementi odvajaju od svojih primarnih tumačenja u procesima rekontekstualizacije i stvaranja specifičnog brikolaža, i na kom kulturnom znanju se zasniva kompetencija za učešće u ovakvim formama kulturne komunikacije.
\end{abstract}

Ključne reči: Vaporwave, muzička kultura, kulturna komunikacija, popularna kultura, značenje i emocija

Uvod

Vaporwave kao muzički žanr s ograničenim brojem uglavnom anonimnih izvođača, ali i veoma ograničenim trajanjem od samo nekoliko godina neretko je opisivan kao „mikro-žanr” među svojom publikom. Validnost primene termina žanr dovedena je u pitanje i kroz pokušaje svođenja vaporwave-a na takozvani „mim"2, čest oblik komunikacije na internetu koji podrazumeva formativne izmene poznate i prepoznatljive osnove - najčešće grafičke, ređe

1 Rad je prvobitno predstavljen na naučnom skupu „Antropologija muzike” održanom 23.3.2018. na Filozofskom fakultetu Univerziteta u Beogradu.

2 eng. meme 
multimedijalne - u cilju komuniciranja određene poruke (Lysloff 2003, 29). S druge strane, ljubitelji i stvaraoci vaporwave-a ukazuju na to da ne samo što se radi o muzičkom žanru, već i o umetničkom pravcu koji izranja iz šireg ,retro pokreta", a čiji se uspeh, shodno tome, temelji na buđenju osećanja nostalgije kod svojih slušalaca.

Ipak, kakav god stav zauzeli prema muzičkim i, kako ću pokazati, multimedijalnim ostvarenjima koja se podvode pod odrednicu vaporwave-a, nepobitna je činjenica da je ovaj žanr popularne kulture u periodu između 2012. i 2016. godine postigao veliki uspeh, uz izuzetan broj ostvarenja koja su prepoznata i doživljena među publikom kao jasno smeštena u okvire žanra i kao neodvojivo povezana sa fenomenom interneta, konceptom ,internet generacije” i, možda najznačajnije, osećanjem nostalgije.

U tom smislu, vaporwave se pokazao kao kadar ne samo da komunicira izvesna značenja, već i da ih komunicira na takav način da se ona, bar u slučaju ljubitelja žanra, dovode u direktnu vezu s veoma specifičnim osećanjem nostalgije za periodom ranih početaka informatičke ere. Povrh toga, iako je u prvom redu shvaćen kao muzički žanr, vaporwave se u svom izrazu ne može odvojiti od prepoznatljivog vizualnog stila koji obuhvata sve one slikovne elemente koje ljubitelji žanra smatraju njegovom značajnom, a u nekom smislu čak i centralnom karakteristikom.

Ove osobenosti vaporwave-a presudno su uticale na formulaciju pristupa tom fenomenu kroz nekoliko neodvojivo povezanih centralnih pitanja - na koji način se tehnike obrade zvuka, vizualne predstave i elementi popularne kulture dovode u međusobnu vezu u okviru muzičkog žanra, čineći ga suštinski multimedijalnim, kako se ti elementi odvajaju od svojih primarnih tumačenja u procesima rekontekstualizacije i stvaranja specifičnog brikolaža i najzad, na kom kulturnom znanju se zasniva kompetencija za učešće u formama kulturne komunikacije koje se podvode pod žanrovsku odrednicu vaporwave-a.

Cilj istraživanja biće da pokaže na koji način vaporwave svojim multimedijalnim izrazom i slojevitom značenjskom strukturom (v. Gerc 1998, 14) izaziva prilično stereotipizovana osećanja, obično protumačena, opisivana i doživljena kao nostalgija, kod onih ljudi koji dele određen korpus kulturnog znanja. Istovremeno, služeći se ovim primerom, obrazložiću tezu o multimedijalnosti kulturnih i umetničkih proizvoda kao njihovom značajnom svojstvu. Najzad, posmatrajući vaporwave kao ekspresivni fenomen popularne kulture, pokazaću da je kulturna komunikacija, posredovana ostvarenjima iz ovog žanra u pogledu svog koda, ukorenjena u različitim trendovima i drugim kulturnim proizvodima koji su mu prethodili, te da je poznavanje šire popularne kulture i njenih određenih značenjskih konvencija u osnovi karakterističnog subjektivnog doživljaja žanra, odnosno, njegovog uspešnog povezivanja sa konceptom nostalgije i drugim značenjima koja mu se pripisuju. 


\section{Vaporwave - nastanak i razvoj žanra}

Vaporwave se prvi put pojavljuje krajem 2011. godine na talasu nekoliko sličnih „mikro-žanrova” koji se smatraju njegovim neposrednim pretečama, a koji se uglavnom podvode pod odrednice chillwave i hypnagogic pop. ${ }^{3} \mathrm{Oba}$ žanra sa sobom donose neke od ključnih svojstava koja će dve godine kasnije obeležiti i vaporwave - sporiji tempo i kreativnu upotrebu reverberacije ${ }^{4}$, sticanje publike putem interneta, ,uradi sam” pristup stvaranju muzike bez profesionalne studijske produkcije i, možda najznačajnije, prihvatanje takozvane „retro estetike" uz posledično okretanje ka predstavama o prošlosti kroz njihovo „oživljavanje” i emuliranje.

Ovo interesovanje za prošlost, te pokušaji njene emulacije putem oponašanja određenih svojstava ostvarenja iz odabranih prošlih perioda karakteristično je za „retro maniju”, čije prisustvo u različitim aspektima savremene popularne kulture - od muzike, preko fotografije, filma, televizije, pa sve do video igara - nije promaklo antropološkom interesovanju (Niemeyer 2014; Angé and Berliner 2016). Karakteristike koje se emuliraju najčešće se tiču stilskih konvencija iz prošlosti, ali i onih svojstava prošlih ostvarenja koja su posledica tehničkih ograničenja muzičke i video opreme tadašnjeg vremena.

Ipak, značajno je primetiti da ovaj „kao da” pristup usmeren ka prošlosti koji predstavlja možda i najprepoznatljiviju karakteristiku kako vaporwave-a, tako i njegovih stiliskih preteča, takođe uključuje i izvesne konvencije, kao što su upotreba specifičnog opsega boja ili upotreba motiva iz određenih ostvarenja popularne kulture, koje se ne mogu dovesti u direktnu vezu bilo sa dizajnerskim stilovima, bilo sa tehnološkim nesavršenostima prošlih perioda, ali koje su postale jednako značajni elementi prepoznatljivog izraza vaporwave-a.

Govoreći o ovoj emulaciji prošlosti karakterističnoj za pomenute muzičke žanrove, anonimni kritičar, koji stoji i iza same kovanice chillwave, slikovito je opisao ovaj muzički žanr u digitalnom časopisu Hipster Runoff kao ,nešto što se čuje u pozadini stare VHS kasete iz kasnih osamdesetih ili ranih devedesetih, koju ste pronašli negde na tavanu". ${ }^{5}$ Upravo ova mogućnost da kod slušalaca

${ }^{3}$ Granice između njih često su nejasne i samim ljubiteljima žanrova, te se oba ponekad podvode pod zajedničku, ali ređe korišćenu odrednicu ,glo-fi”. Čini se da se primarna distinkcija između ovih žanrova zasniva na mestu u kom su nastali, te umetnicima iz prošlosti na koje se ugledaju - konkretno, dok se umetnici iz SAD češće svrstavaju pod odrednicu chillwave-a, oni iz Evrope radije prihvataju odrednicu hypnagogic pop.

${ }^{4}$ Reverberacija je pojava prilikom koje se zvuk čuje i nakon isključenja njegovog izvora usled refleksije i raspršivanja zvučnih talasa. Kod slušaoca je uglavnom prepoznat kao kvalitet ,prostornosti” zvuka. U tekstu, upotreba termina reverberacija odnosi se na tehniku procesuiranja signala (,efekat”) prilikom muzičke produkcije koja oponaša ovu pojavu.

${ }^{5}$ Radi se o tekstu iz digitalnog časopisa Hipster Runoff. Tekst je arhiviran i dostupan na:https://web.archive.org/web/20130717013018/http://hipsterrunoff.com/node/1780 
izazove asocijativni proces koji rezultira tako slikovitim subjektivnim utiskom, odnosno, uspešnim komuniciranjem ,fiktivnog sveta” subjektivno percipirane i doživljene prošlosti, jeste najznačajnija karakteristika koju će vaporwave naslediti od svojih prethodnika.

Nastanak vaporwave-a obično se vezuje za 9. decembar 2011. i objavljivanje albuma Floral Shoppe umetnice koja se tada predstavljala pseudonimom Macintosh Plus. Za ljubitelje ovog žanra, Floral Shoppe je postavio temelje vaporwave-a, kako one muzičke, tako i slikovne - uspostavljajući ono što će sa kasnijim razvojem žanra, a i publike, biti prepoznato kao „estetika”, ili stilizovano, među ljubiteljima žanra, „AESTHETICS”.

U pogledu svojih muzičkih karakteristika, vaporwave se primarno zasniva na obradi i ponovnoj upotrebi već postojećih muzičkih izraza. Mada to ne isključuje mogućnost „originalnih” ostvarenja u okviru žanra (koja svakako postoje), za razliku od svojih neposrednih prethodnika, umetnici vaporwave-a prihvataju i naglašavaju odabir „muzičke osnove”, te tehnike njenog „oneobičavanja” kao svoje glavne i praktično jedine tehnike stvaranja muzike. Dok upotreba postojećih muzičkih komada i prepoznatljivih zvučnih formi (recimo, replike iz popularnih filmova), posebno onih koji potiču iz poslednjih nekoliko decenija dvadesetog veka, nije bila neobična ni u okvirima chillwave-a, za vaporwave „novo" uvek nastaje iz „oneobičavanja” starog.

U pogledu odabira svoje „muzičke osnove”, odnosno, muzičkih komada koji će biti obrađeni i u izmenjenoj formi upotrebljeni kao osnova za stvaranje novih numera, vaporwave se interesuje za popularnu i džez ${ }^{6}$ muziku iz osamdesetih i devedesetih godina dvadesetog veka, a nešto manje i za takozvane „korporacijske džinglove” i „muzak” - muziku iz liftova koji su češće prosto oponašani u originalnim autorskim ostvarenjima. Tehnike obrade zvuka, u prvom redu, zasnivaju se na usporavanju snimaka i kreativnoj i izraženoj upotrebi reverberacije. Svakako najpoznatiji primer upotrebe ovih tehnika jeste pesma Lisa Frank 420/Modern Computing pomenutog izvođača Macintosh Plus, koja je među uživaocima žanra izdvojena kao najreprezentativnija numera, neretko opisivana i kao „himna” vaporwave umetničkog pokreta ${ }^{7}$, a koja se u celini sastoji od usporenih i izmenjenih deonica pesme It's your move Dijane Ros iz 1984.

Okrećući se ka pitanju slikovnih karakteristika vaporwave-a, značajno je primetiti da je samo prisustvo slikovnog u nečemu što se, bar načelno, smatra muzičkim žanrom, u značajnoj meri povezano s internetom kao primarnim kontekstom u kom se kulturni proizvodi smešteni u okvire vaporwave-a dele, cirkulišu i u kom pronalaze put do svojih slušalaca. Uz pojavljivanje ovih ostvarenja na internet portalima kao što su YouTube, Bandcamp, Vimeo ili Reddit, ali i mnogim drugim forumima i društvenim mrežama, nije iznenađujuće da su slike,

6 Takozvani smooth jazz.

7 https://beardedgentlemenmusic.com/2017/11/15/what-the-f-is-vaporwave-part-2/ 
naslovnice „digitalnih albuma" kratke animirane forme, spotovi i drugi slični vizuelni elementi koje je moguće postaviti „na mrežu” uz zvučni zapis postali jednako prepoznatljivi elementi žanra koliko i sami zvučni elementi.

Govoreći o konkretnim slikovnim elementima koji se dovode u direktnu vezu s vaporwave-om, odnosno, o onome što je među ljubiteljima žanra grupisano pod odrednicu „estetika”, možemo pomenuti određene stilske izbore kao što su odabir kolorita, fontova ili već pomenute tehnike „emulacije prošlosti” kao što su distorzija slike u cilju oponašanja VHS snimka ili analogne fotografije sa njihovim karakterističnim nesavršenostima, kao i stvaranje vizuelnih predstava u stilu rane amaterske digitalne umetnosti. Pored toga, veoma značajnu ulogu igraju i konkretne predstave ranih računarskih operativnih sistema, zastarelih konzola za video igre (Sega, Nintendo), monitora sa katodnim cevima, ali i reference na popularnu kulturu devedesetih godina prošlog veka (posebno na crtanu TV seriju „Simpsonovi”).

Vraćajući se ukratko na pitanje interneta kao primarnog konteksta u kom ostvarenja klasifikovana kao vaporwave cirkulišu, bitno je i ukazati na presudni značaj internet portala i društvenih mreža kao mesta na kojima se značenja pridavana ovom žanru pregovaraju i čine javnim u narativnoj formi. Tumačenja vaporwave-a od strane njegove publike kreću se od političko-ekonomskih (bilo da se radi o „otporu poznom kapitalizmu” ili njegovom prihvatanju i slavljenju), do "filozofskih" ili idiosinkratičnih. Ipak, etnoeksplikacija oko koje u publici postoji izuzetan nivo saglasnosti, a koja je često i u osnovi gore navedenih tumačenja, tvrdi da vaporwave izaziva specifičan skup osećanja kod slušalaca koji je u prvom redu obeležen nostalgijom, a koji se izaziva putem delovanja muzike na „kolektivno nesvesno”, „kolektivno sećanje”, „kulturno sećanje” ili već nešto slično tome, zavisno od konkretnog tumačenja.

Ma koliko nejasne bile ove formulacije, sama činjenica da se većina ljudi, upoznatih sa vaporwave-om, slaže da se taj žanr primarno tiče nostalgije, ma kako ona kasnije bila objašnjena i protumačena, ukazuje na jasnu povezanost svega onoga što sačinjava vaporwave sa specifičnim afektivnim setom, ali i na činjenicu da se ta povezanost temelji na specifičnom korpusu kulturnog znanja koje, kako se čini, nadilazi specifične geografske, pa i kulturne lokalnosti.

\section{Lični doživljaj muzike kao tumačenje značenjsko-afektivnih asocijacija u multimedijalnoj kulturnoj komunikaciji}

U svojoj osnovi, teorijsko-metodološki pristup istraživanom fenomenu biće nedvosmisleno semiotički, postavljajući u centar analize značenja koja se pripisuju vaporwave-u, ali i mnogo značajnije, sisteme značenja na kojima je ovaj fenomen zasnovan. Govoreći o predmetu etnografije, Kliford Gerc piše o 
„slojevitoj hijerarhiji značenjskih struktura" u čijim okvirima se različiti komunikacijski činovi opažaju i tumače i „,bez kojih oni ne bi zapravo ni postojali” (Gerc 1998, 14) i upravo ovo može biti polazna tačka izlaganja svih onih teorijskih premisa kojima ću se služiti u daljem tekstu.

Ukoliko sagledamo konkretna ostvarenja klasifikovana pod žanrovsku odrednicu vaporwave-a kao jedinstvene, mada kompleksne komunikacijske činove, predmet ovog istraživanja postaju sve one značenjske strukture koje omogućavaju tim komunikacijskim činovima da budu prepoznati kao takvi, da budu protumačeni i doživljeni na specifičan način - drugim rečima, da postoje kao opažljivi, osobeni i relevantni kulturni artefakti koji cirkulišu u određenom kontekstu gde su prepoznati kao takvi, i gde imaju svoj „život među publikom” koji se zasniva na procesima „kulturne recepcije i askripcije kulturnih značenja” (Žikić 2012, 316). Ovi procesi omogućavaju različitim muzičkim (i multimedijalnim) formama da budu prepoznate „kao vaporwave” sa svim što ta odrednica podrazumeva u značenjskom, ali i afektivnom smislu. Oni predstavljaju upravo ono "deljenje, razgraničavanje i razvrstavanje na takozvane muzičke pravce, stilove ili žanrove” koje oblikuje „naš lični odnos” i „naše kulturno ponašanje” prema datoj muzičkoj celini (Žikić 2009, 339).

Ovim procesima, kako piše Bojan Žikić, sami upravljamo „u okviru mogućnosti koje su nam kulturno ponuđene", pri čemu se orijentišemo ne samo prema „unutrašnjim svojstvima samog muzičkog komada”, već i prema tome „koji kulturni kognitivni model on aktivira” (Žikić 2009, 345). Na taj način, muzika postaje „Zvučni prostor ispunjen značenjima” (Ristivojević 2012, 471), kako usled njene otvorenosti za upisivanje određenih značenja, tako i usled postojanja kompetencije za tumačenje poruka kodiranih u njoj među publikom. I jedno i drugo nalazi se u osnovi prevazilaženja ,inicijalne idiosinkratičnosti umetničkog čina” (Žikić 2010, 28), i jedno i drugo ukazuju na „deljenu prirodu kulturne komunikacije", odnosno činjenicu da i oni koji oblikuju informacije - u ovom slučaju stvaraoci vaporwave-a - i oni kojima su te informacije namenjene - slušaoci - moraju poznavati kod kulturne komunikacije koja se odvija posredstvom datih kulturnih artefakata (Žikić 2010, 28), odnosno moraju deliti isti korpus kulturnog znanja.

Dakle, učešće u kulturnoj komunikaciji posredovanoj ostvarenjima popularne kulture jeste ,stvar kulturne mogućnosti, a ne kulturne neumitosti” (Žikić 2009, 343), odnosno, do njega dolazi samo ukoliko pojedinac poseduje određeno kulturno znanje koje stiče ,,iskustvom života u određenoj sredini, te formalnim i neformalnim učenjem" (Žikić 2012, 330). Kada govorimo o popularnoj kulturi, ta sredina jeste popularna kultura sama (Žikić 2012, 330), a procesi neformalnog učenja u prvom redu podrazumevaju ,praćenje dešavanja u jednom ili više njenih vidova" (Žikić 2012, 330). 
Ukoliko sagledamo popularnu kulturu kao ,interkontekstualno cirkulisanje odgovarajućih kulturnih proizvoda, te kontekstualno uslovljene promene u njihovim vrednostima i značenjima" (Žikić 2012, 316), to implicira da se relevantno kulturno znanje potrebno za učešće u kulturnoj komunikaciji posredovanoj ostvarenjima popularne kulture prvenstveno tiče poznavanja kulturnih proizvoda koji cirkulišu u datom značenjskom kontekstu, „trendova”, viralnih i popularnih formi i ostvarenja, te ispravnog mapiranja vrednosti i značenja koji im se $\mathrm{u}$ datom trenutku pridaju.

Ali, ni procesi cirkulisanja kulturnih proizvoda, ni promene njihovog značenja ne bi bili mogući, makar ne u obimu i na nivou složenosti koji karakterišu savremenu popularnu kulturu, da samo kulturno stvaralaštvo nije „kumulativno po sebi", odnosno, da se kulturni izrazi na neki način ne nadovezuju na delove ranijih kulturnih izraza ,u istorijskoj perspektivi i ne ograničavajući se na formu ili sadržaj" (Žikić 2012, 332). Ova premisa veoma je značajna budući da ukazuje ne samo na to da su ostvarenja popularne kulture zasnovana na određenim konvencijama, već i da te konvencije imaju svoju istoričnost.

Dakle, jasno je da „muzika nije kategorija koja 'visi u vazduhu', lišena sredine koja je okružuje", već je ona, naprotiv, ispunjena značenjima i određena upravo svojom (značenjskom) sredinom (Ristivojević 2013, 444). Ona je povezana s izvesnim ostvarenjima koja su joj prethodila i smeštena u centar mreže značenja i asocijativnih odnosa koja je od ključnog značaja za samo „iskustvo slušanja", jer upravo ta mreža odnosa predstavlja ono što usmerava i oblikuje naš subjektivni doživljaj i tumačenje muzike (Oltețeanu 2010, 12), u skladu sa deljenim kulturnim znanjem koje posedujemo i našim ličnim sećanjima koja igraju značajnu ulogu u organizovanju i povezivanju različitih delova našeg kulturnog znanja (Finnegan 2003, 192).

Ovakva teorijska postavka neminovno vodi ka tezi da su tumačenje i lični doživljaj muzike zasnovani na aktivaciji različitih konekcionističkih šema, odnosno, kognitivnih ili kulturnih modela, shvaćenih kao fleksibilnih i adaptivnih mentalnih struktura izgrađenih od međusobno povezanih i isprepletanih mreža elemenata (Strauss and Quinn 1997, 53-54) koje organizuju povezane delove našeg znanja i na taj način utiču na procesuiranje informacija (Strauss and Quinn 1997, 49). Posledično, utiču na interpretaciju i subjektivni doživljaj ma kog događaja, ideje ili fenomena. Jednako značajno, kognitivne šeme pružaju pojedincu velike količine od ranije dostupnih informacija koje usmeravaju interpretaciju i vode nas dalje od one informacije koja je prvobitno aktivirala datu kulturnu šemu (Strauss and Quinn 1997, 49), što znači da naša prethodna iskustva i prethodno stečena kulturna znanja u značajnoj meri oblikuju naša buduća tumačenja društvene stvarnosti.

Dakle, vraćajući se na pitanje muzike, možemo izneti tvrdnju da ne moraju svi elementi mreže značenja i asocijacijativnih odnosa, koji usmeravaju doživljaj 
i tumačenje onoga što čujemo, biti prisutni u muzičkom komadu samom. Oni mogu biti, i veoma često jesu, ,indirektno” prisutni - u našem sećanju i našem kulturnom znanju, akitivirani putem značenjskih i asocijativnih veza sa drugim direktno prisutnim elementima i na taj način uključeni u složen proces interpretacije. Ti ,indirektno pristuni elementi”, dakle, predstavljaju kulturne kognitivne modele, mentalne slike, predstave koje nadilaze zvuk kao, uslovno rečeno, primarni komunikacijski kanal. Ipak, ovo nije nimalo neobično - kako Edmund Lič piše, „na jednom dubljem, apstraktnom nivou, sva naša čula, iako različita, kodirana su na isti način" (Lič 2002, 20), što nam omogućava da zaključimo da „komunikacijski kanal nije analitički bitan sam po sebi” (Žikić 2010, 28), a značenja koja se komuniciraju muzikom mogu se komunicirati i nekim drugim komunikacijskim kanalom drugačije forme.

Na kraju krajeva, upravo ova ,prevodljivost činjenice na različite diskurzivne nivoe”, jeste prema Levi-Strosu, nešto što predstavlja samu suštinu značenja, i to takvu da ona zahteva postojanje izvesnih ,pravila prevoda” (Levi-Stros $2009,16)$. Levi-Stros nije usamljen u ovoj tvrdnji, kako i Lič piše o postojanju logičkog mehanizma koji nam omogućava da vizualne poruke transformišemo u auditivne i obrnuto (Lič 2002, 20). Baveći se užom problematikom muzike, ovaj fenomen primećuju i Alan Meriam, koji ga definiše kao „asocijativnu sinesteziju" (Merriam 1964, 86), i Malkolm Bad koji ga tumači u skladu s Ličovom postavkom (Budd 1992, 47). Svi ovi autori, dakle, ukazuju na to da ne postoji nikakva suštinska razlika između poruka komuniciranih različitim kanalima komunikacije i svi oni ukazuju da se različiti modaliteti komunikacije mogu mešati i prevoditi jedan $u$ drugi.

Ali, na ovom mestu bih izneo još jednu tvrdnju - multimedijalnost implicira ne samo mogućnost prevođenja muzičkih elemenata u, recimo, slikovne, već i mogućnost istovremenog i jedinstvenog komunikacijskog doživljaja koji se zasniva kako na zvučnim, tako i na slikovnim, narativnim ili nekim drugim elementima. Drugim rečima, multimedijalnost podrazumeva istovremeno prevođenje značenja komuniciranih različitim čulnim kanalima u jedinstven doživljaj koji se više ne tiče ni jednog od uključenih čulnih kanala, već mentalnih slika, logičkih mehanizama i kognitivnih šema u ljudskom umu koji objedinjuju i nadilaze svaki od pojedinačnih komunikacijskih kanala prisutnih u datom komunikacijskom događaju.

Ovakvo shvatanje multimedijalnosti kulturne komunikacije zasnivaću na Ličovom shvatanju obreda kao "komunikacijskog doživljaja” koji se ostvaruje putem „mnoštva različitih čulnih kanala istovremeno" (Lič 2002, 63). Mada se Lič u analizi obreda ne bavi detaljnije pitanjem muzike, on pokazuje da obred uključuje niz različitih komunikacijskih kanala (pa, tako i muziku) koji svi igraju ulogu u komuniciranju jedinstvene poruke. Istovetno tome, moguće je tvrditi da već pomenuti slikovni elementi kao što su naslovnice albuma, spotovi ili 
animirane forme koji se dele uz sama muzička ostvarenja prepoznata kao vaporwave i sami doprinose specifičnom izrazu žanra. To bi značilo da ni zvučni ni slikovni elementi ne mogu obuhvatiti totalitet značenja koja se komuniciraju ovim formama. Odgovor na pitanje šta vaporwave znači za svoje slušaoce i stvaraoce može biti pronađen samo ukoliko sagledamo i zvučne i slikovne elemente kao deo jedne iste poruke.

Multimedijalnost nije karakteristika samo vaporwave-a, već i drugih muzičkih žanrova, a do primera možemo doći ako se zapitamo, recimo, da li možemo razmišljati o grunge muzici, a da ne pomislimo na ,starke" i flanelske košulje, o reggae muzici bez ikonografije Rastafari pokreta ili o hip-hopu bez stereotipnih predstava o getu i rasnim tenzijama u Sjedinjenim državama. Svaki od ovih žanrova ima i svoj prepoznatljiv slikovni izraz koji je asocijativno povezan i s određenim zvučnim elementima koji se pripisuju žanru, i s određenim izvođačima, ali i sa predstavama, pojmovima i objektima koji daleko nadilaze okvire muzičkog, pa čak i umetničkog. Sve ove relacije presudno utiču na naš lični doživljaj date muzičke celine. Kako piše Bojan Žikić, ,neka muzika nam se sviđa zbog toga što zvuči kako zvuči, jednostavno, ali prema nekoj razvijamo afinitet (...) zbog onoga iz sociokulturne stvarnosti sa čim je povezujemo značenjski, ali emotivno i afektivno, takođe" (Žikić 2009, 345).

Dakle, kao i sve druge umetnosti, a možda i kao svi drugi kulturni proizvodi šire, muzika se ne tiče samo značenja, već i osećanja, sa veoma nejasnom i teorijski problematičnom granicom između ta dva koncepta, usled čega je neophodno teorijski se odrediti i prema ovom problemu. U tom cilju, poći ću od shvatanja tela ne kao objekta, već kao subjekta i „egzistencijalne osnove kulture" (Csordas 1990, 5), što nam omogućava da u pogledu teorijskog određenja prema problemu osećanja zauzmemo „konstruktivističku poziciju”, tvrdeći da su emocije, kognitivni procesi i sama percepcija neodvojivi i nerazlučivi procesi u ljudskom umu (Christensen 2018; de Munck 2013).

To znači da učeći kulturu, mi učimo i stereotipizovane afektivne sisteme, te značenjske sisteme kojima se oni komuniciraju, a samim tim, naša potonja tumačenja određenih kulturnih proizvoda, fenomena ili situacija, usmerena našim sećanjem, odnosno, stečenim kulturnim znanjem i kognitivnim šemama koje to znanje organizuju, ticaće se ne samo značenja, već i osećanja, što zauzvrat igra ključnu ulogu u samom „oblikovanju iskustva” (Berger 2009, 11). Ovakva postavka oslanja se na shvatanje Džona Levita koji smatra da emocije nisu samo znakovi već iskustva značenja/osećanja ${ }^{8}$ koja su organizovana i posredovana putem znakovnih sistema (Leavitt 1996, 530). Kao takve, emocije uključuju i kulturno značenje i telesni osećaj - one se subjektivno osećaju i interpretiraju, ali socijalizovana ljudska bića, „misleća tela” su ona koja ih osećaju u određenim društvenim kontekstima (Leavitt 1996, 531).

8 eng. meaning/feeling experiences

Етноантрополошки проблеми, н.с. год. 13 св. 4 (2018) 
Iz ove perspektive, Levit zaključuje da su emocije društveno i kulturno deljene, i komunicirane među grupama i pojedincima, pojavljujući se prilično stereotipizovano u skladu sa ponavljajućim društvenim situacijama i kulturnim definicijama njihovog vrednovanja (Leavitt 1996, 527). U tom smislu, identično semantičkim asocijacijama, i afektivne asocijacije direktno su povezane sa zajedničkim iskustvima i izloženošću pričama, pesmama, slikama ili drugim kulturnim proizvodima koji se tiču predstave o određenom afektivnom setu (Leavitt 1996, 527).

Takav pristup omogućava nam ne samo da afektivne sisteme posmatramo kao analogne kognitivnim šemama, već i da izbrišemo granicu između ta dva koncepta, prihvatajući, naprotiv, da kulturni proizvodi mogu komunicirati i semantička i afektivna značenja istovremeno, pri čemu uspešnost oba aspekta komunikacije zavisi od posedovanja određenog korpusa kulturnog znanja neophodnog za kodiranje, odnosno dekodiranje poruke.

\section{Konstrukcija nostalgije u digitalnim medijima}

Povezanosti između vaporwave-a i interneta, koje su svakako kompleksne i višestruke, pomenute su nekoliko puta u dosadašnjem izlaganju - internet se pojavljuje kao digitalni prostor u kom ostvarenja vaporwave-a cirkulišu i u kom su deljena, on je primarni kanal putem kog ova ostvarenja dolaze do publike, mesto pregovaranja njegovih značenja, ali i u značajnoj meri inspiracija i predmet interesovanja samog žanra. Stoga, jasno je da će biti neophodno teorijski se odrediti prema konceptu interneta.

Prihvatajući „mrežu” kao veoma kompleksan društveni i kulturni fenomen, napomenuo bih da njegovo detaljno razmatranje značajno nadilazi obim i temu ovog teksta. Umesto toga, pristupiću određenju interneta kao „oruđa” proizvodnje i komunikacije određenih kulturnih proizvoda čija se upotreba oslanja na „kreativne strategije tehnološke adaptacije” društvenih grupa i činjenicu da se kulturne forme zasnivaju i komuniciraju na onim resursima, odnosno, onim kanalima komunikacije koji su dostupni u datom kontekstu (Lysloff 2003), što u ovom slučaju uključuje digitalne resurse, sredstva njihove obrade, društvene mreže i internet portale. Kao prostor komunikacije, internet postaje mesto susreta pojedinaca i grupa, a „biti na mreži” znači učestvovati u ,paralelnoj društvenoj realnosti dostupnoj putem Interneta" (Žakula 2012, 48), u kojoj korisnici stvaraju sopstvene lične i ekspresivne reprezentacije (Žakula 2012, 51) i konzumiraju sadržaje koje su kreirali drugi korisnici.

Govoreći o ovoj interakciji u sajberprostoru, Gabriela Kolman napominje da, kada god pojedinci i grupe komuniciraju posredstvom digitalnih medija, dolazi do cirkulacije, prevođenja, brisanja, preuveličavanja, revizija, ponovnih promišljanja 
i najrazličitijih formi upotrebe i konzumacije kulturnih predstava, iskustava, ali i identiteta, budući da digitalni mediji igraju značajnu ulogu u formiranju novih grupa čiji pripadnici vezuju svoj osećaj sopstva, shvatanje profesije ili društvene pripadnosti upravo za digitalne tehnologije (Coleman 2010, 488). Ali, i pored činjenice da upotreba računara, interneta, pa čak i društvenih mreža za mnoge nije pitanje dokolice, već rada i krajnje ozbiljnosti, za „običnog” korisnika koji ne upotrebljava internet, bar ne uvek, za privređivanje i za rad (Bakardjieva 2005, 69), on postaje ,prostor dokolice” (Spracklen 2015, 11) koji je kao takav u opoziciji i, u izvesnom smislu, suprotstavljen radu (Tarner 1989, 62, 64).

Ali, prihvatajući internet kao fenomen liminoidnog u Tarnerovom shvatanju tog termina, istovremeno prihvatamo i autorovu ideju o „dva tipa sloboda”. Dakle, ne samo što je vreme provedeno ,na mreži” vreme „slobode od” institucionalnih obaveza i ritmova, već je ono direktno povezano i sa Tarnerovom idejom „slobode za osvajanje i stvaranje novih simboličkih svetova” (Tarner 1989, 72). U tom smislu, možemo reći da „biti na mreži”, kao forma razonode, otvara mogućnost korisnicima da se ,igraju” elementima poznatog, „oneobičavajući” ih, pri čemu ,novo nastaje iz nečuvenih kombinacija poznatih elemenata” (Tarner 1989, 51). U kontekstu Web-a 2.0 (Žakula 2012, 46), to znači da korisnici mogu ne samo otkrivati nove simboličke svetove, već i aktivno učestvovati u njihovom stvaranju putem različitih tehnika stvaranja „novog”.

Ipak, a posebno kada govorimo o internetu, te tehnike najčešće podrazumevaju ono što Rene Lislof naziva „kopiraj-i-zalepi kreativnošću” (Lysloff 2003) koja se, istovetno vaporwave-u samom, zasniva na rekontekstualizaciji, obradi i ponovnoj upotrebi različitih elemenata u cilju stvaranja specifičnog brikolaža. Ova „kultura remiksa, patine i ponovne upotrebe” koja se razvija na internetu (Bartholeyns 2014, 52), brzo je postala blisko povezana s nostalgijom, čak i pre pojavljivanja vaporwave-a. Zapravo, početak 21. veka obeležen je u značajnoj meri ,porastom izraza nostalgije, nostalgijskim objektima, medijskim sadržajima i stilovima” (Niemeyer 2014). „Digitalizacija retro stila” učinila je jedan deo interneta ,nalik velikom tavanu ili buvljaku gde se individualne i kolektivne nostalgije stapaju i šire" (Niemeyer 2014, 1).

„Retro pokret” nije prošao nezapaženo u društveno-humanističkim naukama. Mark Fišer, koji se bavio pretečama vaporwave-a, ,retro pokretom” i nostlagijom u muzici, tumačio je ovaj fenomen uz pomoć ponovnog promišljanja Deridinog koncepta „utvarologije”, dajući mu izvesnu političku konotaciju i pristupajući mu kao manifestaciji „,nostalgije za izgubljenim budućnostima” (Fisher 2014). Drugi autori su pisali o „,̌ežnji za onim čega manjka u sadašnjosti", što je nedostižno usled same prirode vremena (Pickering and Keightley 2006), o „dramatizaciji diskontinuiteta” i želji da se „uhvati” ono što je život bio nekada (Angé and Berliner 2016).

9 eng. Copy ' $n$ ' Paste creativity 
Ne zalazeći dublje u pitanje zašto je „retro” toliko živ u 21. veku, Dominik Šrej piše da mediji funkcionišu kao sredstvo „virtualnog pristupa prošlosti”, te da kao takvi postaju značajni resursi „kulturnog sećanja” (Schrey 2014, 29). U tom slučaju, ono što se doživljava kao nostalgičnost proizlazi bilo iz stila medijske reprezentacije, bilo iz medija samog, u kom slučaju se osećanje nostalgije usmerava ka specifičnoj medijskoj konstituciji, znakovima materijalnosti medija, te estetici koja proizilazi iz ovih faktora ili svemu tome skupa (Schrey 2014).

To je posebno vidljivo u slučaju fotografije - jednom kada je digitalna fotografija dostigla „optičko savršenstvo", postajući rezultat automatizovanih i visoko efikasnih tehničkih i digitalnih procesa, ona je sve češće opisivana kao „hladna” i ,udaljena” u odnosu na ,živu” analognu fotografiju (Bartholeyns 2014, 51), a nostalgija je bila usmerena sve više ka „toploti” analogne fotografije, a sve manje ka ljudima i stvarima koji su bili predstavljeni na njima. Prepoznajući ovaj trend, proizvođači digitalnih foto-aparata, ali i programeri specijalizovani za razvoj aplikacija za ,pametne telefone”, počeli su da nude javnosti filtere koji simuliraju sve one karakteristike i nesavršenosti analogne fotografije koje su odsutne iz digitalne (Bartholeyns 2014, 51), upravo u skladu s idejom o „nostalgičnosti medija” o kojoj govori Šrej (Schrey 2014). Na pitanje filtera ću se ponovo vratiti u kasnijem izlaganju.

Ono što je bitno naglasiti na ovom mestu jeste snažna argumentacija u prilog tvrdnji da se ovde ne radi o „generacijskom efektu”, budući da najveći broj onih zainteresovanih za emulaciju prošlosti, uz pomoć digitalnih „mimetičkih” tehnologija, jesu „digitalni nativci”, ljudi koji nisu deo generacije koja je iz prve ruke iskusila ono što teži da emulira (Bartholeyns 2014, 52-54). Čini se da lična povezanost $\mathrm{s}$ datom tehnologijom ili estetikom uopšte nije značajna, budući da je „nostalgizacija” ma kog objekta moguća uz pomoć „estetike”, uz pomoć onih tehnika koje će usmeriti našu interpretaciju onoga što vidimo (ili čujemo) u zamišljenom smeru (Bartholeyns 2014, 57). Drugim rečima, u digitalnim medijima nostalgija je konstruisana putem različitih „mimetičkih” tehnika čiji je centralni zadatak da usmere interpretaciju datog objekta, da ga smeste u određene značenjske, ali i afektivne okvire.

\section{Analiza}

Polazeći od zvučnih karakteristika vaporwave-a, možemo ukazati na nekoliko značajnih elemenata - odabir muzičke osnove, njeno usporavanje, te kreativna upotreba reverberacije. Kako bismo razumeli na koji način ove karakteristike usmeravaju doživljaj muzičke celine kod publike, odnosno, koje kognitivne kulturne modele one aktiviraju (i koja osećanja izazivaju kod slušalaca), predlažem da razmotrimo svaki od ovih elemenata ponaosob, obraćajući pažnju na istoričnost njegove upotrebe u kontekstu popularne kulture. 
Odabir muzičke osnove pokazuje da se vaporwave interesuje za muziku koja je bila popularna u onim periodima čiji stilski izraz ovaj žanr teži da emulira, dakle, u kasnim osamdesetim i ranim devedesetim godinama prošlog veka. Radi se najčešće o muzici koja je bila široko popularna i koja je kao takva neopterećena drugim značenjima. ${ }^{10}$ Onda kada se radi o autorskim ostvarenjima, stvaraoci vaporwave-a pokazuju interesovanje za korporacijske džinglove, muziku iz liftova, kao i ambijentalnu muziku, odnosno sve one žanrove koji su značenjski neopterećeni i koji se, u prvom redu, mogu povezati s određenim društvenim, ali i fizičkim kontekstima. Radi se o onim prostorima koje možemo smatrati ,antropološkim nemestima”, tranzitornim prostorima postmodernog doba, prostorima „,ugovorne usamljenosti” (Ože 2005) koji su karakteristični za urbane sredine industrijalizovanih društava.

Usporavanje i reverberaciju, druge dve karakteristike koje presudno utiču na zvučni izraz vaprowave-a, ne možemo smatrati „konvencionalnim” muzičkim elementima, već pre produkcijskim tehnikama. Kao takvi, ovi elementi spadaju u one muzičke delatnosti koje se obično nazivaju produkcijom, post-produkcijom ili „masteringom”, a koje se oslanjaju na niz različitih tehnika obrade zvučnog signala (primene takozvanih „efekata”). Ove tehnike su u potpunosti usmerene na ono što Bojan Žikić naziva „opštim sazvučjem” ili „soničnom bojom” (Žikić 2009, 345) koja je kao takva prepoznatljiva karakteristika za publiku koja poseduje određeno kulturno znanje - koja zna „šta da sluša” (Berger 2009).

Dakle, produkcijske tehnike ne samo što utiču na doživljaj i tumačenje muzike kod slušalaca, već su one daleko prepoznatljivije nego što se može činiti na prvi pogled, što znači da ih možemo smatrati jednako relevantnim muzičkim svojstvima kao što je to slučaj s odabirom instrumenata ili ritmom, recimo. Pritom, ove tehnike i prakse oblikovanja, odnosno obrade zvučnog signala „nisu samo oruđe za praktične ciljeve, već fenomeni koji nose kulturna značenja i emotivnu investiranost" (Perlman 2003, 346). U tom smislu, sledeći cilj je otkriti koja su to kulturna značenja upisana u produkcijske tehnike primenjivane u vaporwave-u, te za koja „emotivna stanja” ova svojstva funkcionišu kao „,uobičajene asocijacije" prema izvesnim kulturnim konvencijama (Robinson 2005, 301) prisutnim u popularnoj kulturi. Robinson piše da muzika i njeni elementi mogu izražavati emociju, a da to nije ničija emocija posebno (Robinson 2005, 300) što znači da, otkrivajući značenja upisana u muziku, po Livitu moramo težiti otkrivanju i ,potencijalnih afekata” upisanih u nju (Leavitt 1996, 532). Ovom zadatku pristupićemo uz obraćanje pažnje na istoričnost konvencija koje određuju date elemente, značenjski i afektivno, odnosno, na načine na koje su oni korišćeni u popularnoj kulturi.

${ }^{10}$ Ovo nije slučaj sa nekim drugim žanrovima koji su inspirisani vaporwave-om i koji su nastali ,nakon” njega.

Етноантрополошки проблеми, н.с. год. 13 св. 4 (2018) 
Govoreći o sporijem tempu, nije potrebno mnogo primera za tvrdnju da se u popularnoj muzici niži broj otkucaja u minuti ${ }^{11}$ obično dovodi u vezu sa baladama, te numerama koje se tiču tuge, nostalgije, sete, žaljenja, očajanja i drugih osećanja iz sličnog afektivnog skupa, u zavisnosti od potreba i preferenci konkretnog žanra, naravno, a na sličan način kao što se durske skale obično opisuju kao „srećne”, a molske kao uglavnom „tužne”. Takve kulturne konvencije Džudit Beker dovodi u vezu sa „habitusom slušanja”, naglašavajući povezanost između opažanja onoga što doživljavamo kao emociju muzičkog komada i naučenih asocijacija i interakcija (Becker 2004, 71), govoreći u prilog tezi da se afektivne reakcije na muziku uče tokom života u određenoj kulturnoj sredini, a u slučaju popularne kulture, kroz praćenje njenih relevantnih formi (Žikić 2012, 330).

Reverberacija, u smislu studijskog efekta, primenjuje se skoro onoliko dugo koliko postoji i muzička produkcija kako bi se „suvim” studijskim snimcima iz „gluvih soba" dodao precizno kontrolisan privid prostornosti. Ipak, već 1947. godine numera Peg o' my Heart u izvođenju grupe The Harmonicats ukazuje na potencijal za drugačiju, kreativnu upotrebu ovog efekta gde su njegova izraženost i zvučna tekstura takvi da se više ne može raditi o emuliranju bilo kakve poznate ili čak „realne” prostornosti.

Jedan od prvih žanrova koji je uz primetnu pravilnost koristio reverberaciju u cilju stvaranja specifične, ,nadrealne” sonične teksture jeste ,psihodelični rok" s izvođačima kao što su The Beatles, Pink Floyd, ili Džimi Hendriks. S druge strane, pioniri $d u b$ muzike kao što su The Upsetters ili Kejt Hadson stopili su izrazitu upotrebu reverberacije sa specifičnim podžanrom rege muzike sredinom i krajem sedamdesetih godina prošlog veka, a tokom devedesetih godina, u Velikoj Britaniji, pojavila su se dva nova žanra čija se sonična tekstura u velikoj meri zasniva na kreativnoj upotrebi reverberacije, naime shoegaze i trip-hop. Prvi od njih značajno je uticao na žanrove koji su se pojavili nešto kasnije, a koji su koristili sličan odabir muzičkih instrumenata (blackgaze, post-rock, post-hardcore), dok je drugi presudno uticao na karakterističan zvuk mnogih „minimalistički-nastrojenih” izvođača kao što su Low ili Lana del Rej.

Kako u svim ovim primerima, tako i u slučaju znatno ,savremenijih” žanrova kao što je, recimo, future garage, reverberacija ostaje nezaobilazna karakteristika muzičkih komada koji teže da komuniciraju ono što možemo nazvati emocijom ili atmosferom koja se vezuje za ideju ličnog, subjektivnog, intimnog, senzualnog, unutrašnjeg i afektivnog. Svi pomenuti žanrovi, mada različiti prema instrumentalizaciji, ritmici, pa i tematici, u svojoj osnovi teže da komuniciraju nešto što je pitanje tog afektivnog skupa. „Atmosferičnost”, kao epitet koji se često pripisuje i samom efektu reverberacije i pomenutim žanrovima koji ga koriste u značajnoj meri, dodatno ukazuje na to da se ova zvučna karakteristika, u kontekstu

11 eng. beats per minute (BPM), uobičajena mera tempa u muzici, posebno onda kada se ona komponuje primenom digitalnih tehnologija. 
popularne muzike, tiče nečega što se može lično osetiti i doživeti, pre nego opaziti ili saznati, vezujući tako specifičan afektivni skup za tumačenje čitavog muzičkog komada i namećući slušaocu, u izvesnom smislu, poziciju subjekta.

Čak i ukoliko izađemo izvan okvira muzike i okrenemo se ka popularnoj kulturi u širem smislu, možemo naići na veoma interesantne primere - recimo, možemo pomenuti zvuk harfe s izrazitom reverberacijom koji se često koristi u filmovima, serijama i crtanim filmovima kako bi označio prelaz iz narativnog „ovde i sada” u san ili subjektivno prisećanje (flešbek) nekog od likova, ili primenu reverberacije na sam glas glumca kako bi se naglasila distinkcija između govora i unutrašnjeg monologa. Ukoliko se setimo Levi-Strosove opaske da ,ako se besmislica pojavljuje sa izvesnom pravilnošću, očigledno nije reč o besmislici" (Levi-Stros 2009, 16), možemo reći da se upravo ovaj značenjsko-afektivni potencijal reverberacije, koji počiva na datoj kulturnoj konvenciji, nalazi u osnovi ,pravilnosti” njene upotrebe.

Razmatranje zvučnih svojstava vaporwave-a nam je omogućilo da steknemo donekle jasniju predstavu o tome kako ostvarenja ovog žanra usmeravaju njihovo tumačenje i lični doživljaj, služeći se kulturnim konvencijama koje imaju svoju istoričnost u okvirima popularne kulture. Vaporwave već odabirom svoje muzičke osnove ukazuje na prošlost - opredeljujući se za one numere koje su komponovane kasnih osamdesetih i ranih devedesetih godina prošlog veka. Čak i onda kada obrada postojeće osnove izostaje, ostvarenja vaporwave-a teže da nam pruže neke odrednice, ako ne vremenske (recimo, uz pomoć upotrebe „toplog" zvuka analognih sintisajzera koji takođe ukazuje na isti period iz prošlosti), onda svakako prostorne, oponašajući muziku koju očekujemo da čujemo na aerodromima, u liftovima, ili prosto na radiju, negde u prolazu, u gradu, u svetu koji nam je poznat.

Istovremeno, specifične produkcijske tehnike oblikuju ove odrednice, čineći ih setnim, tužnim (usled sporijeg tempa), ali istovremeno i ličnim, unutrašnjim, introspektivnim (usled reverberacije). Ako nas vaporwave asocira na neko vreme ili neko mesto, interpretacija će nas voditi ka ličnom doživljaju tog vremena ili mesta, ka onome što to vreme ili mesto ,znače” za nas. Iako bi bilo moguće postaviti pitanje da li „nostalgičnost”, pripisivana vaporwave-u, proizlazi iz upravo ove kombinacije zvučnih elemenata (odnosno, kulturnih i kognitivnih modela koje oni aktiviraju), jasno je da bi takvo tumačenje bilo pojednostavljeno i ono bi ispustilo iz vida drugi, ne-zvučni aspekt vaporwave-a, naime, sve ono što ljubitelji žanra podvode pod odrednicu „estetika”.

Taj termin se odnosi na sve one slikovne elemente koji su postali neodvojivo povezani s ovim muzičkim žanrom kao što su specifičan kolorit, odabir fontova i drugih grafičkih elemenata, slikovne predstave, reference na popularnu kulturu devedesetih godina prošlog veka i dizajnerske tehnike obrade tih elemenata. U razmatranju ovih karakteristika vaporwave-a, okrenućemo se ka Tarnerovim 
idejama liminoidnog (Tarner 1989, 62, 64), te nastanku novog iz „nečuvenih kombinacija poznatih elemenata" (Tarner 1989, 51) imajući na umu Lislofovu ideju „kopiraj-i-zalepi kreativnost” karakterističnu za internet (Lysloff 2003). Dakle, centralno pitanje postaje pitanje rekontekstualizacije, odnosno, stvaranja specifičnog brikolaža kao centralnog mehanizma izranjanja „estetike”, pitanje kako ovi elementi postaju deo jedne celine. U tom smislu, biće neophodno razmotriti načine na koje se poznati elementi popularne kulture odvajaju od svog originalnog konteksta, te ponovo integrišu u novi okvir, uz određena „pravila oneobičavanja” koja karakterišu „estetiku” vaporwave-a.

Ako usmerimo pažnju na odabir slikovnih elemenata koji se koriste u ,estetici" vaporwave-a, lako možemo primetiti izraženu tenziju između starog i novog, između ,futurističkog” i ,zastarelog”. Operativni sistemi pre Windows-a XP (dakle, oni koji su izašli na tržište pre 2001.), konzole za video igre iz devedesetih godina prošlog veka, rana amaterska digitalna umetnost, CRT monitori i slični elementi predstavljaju objekte koji su, u trenutku svog pojavljivanja, u javnosti bili doživljeni kao trijumf tehnološke inovacije (a njihove tadašnje predstave kao primeri savremenog grafičkog i dizajnerskog stila), najnoviji proizvodi u ponudi, ali koji danas mogu biti sagledani samo kao nešto što je rabljeno, što je imalo svoj kulturni život među korisnicima i što je, najzad, prevaziđeno, zastarelo, što je postalo u značajnoj meri „strano” sadašnjem trenutku.

Ova tenzija između novog i zastarelog (prošlog) dodatno je naglašena čestom upotrebom reklama za date uređaje ili programe iz vremena kada su oni predstavljali najnoviju reč tehnologije. Čak i kada to nije slučaj, te „zastarele” tehnologije predstavljaju se u ,estetici” vaporwave-a kroz izvesnu prizmu „futurizma" koja je posebno izražena kada se ta tehnološka ostvarenja dovode u vezu sa funkcionalnošću savremene tehnike, ili kada im se pridaju ,naučno-fantastična" svojstva. Opozicija koja se stvara na ovaj način je jasna - komunikacijski čin koji dati objekat (hardverski ili softverski, bez razlike) predstavlja kao nov, aktuelan, savremen, futuristički ili poželjan, stoji u jasnoj i direktnoj opoziciji s kulturnim znanjem savremenog korisnika računara, koji prepoznaje proizvod kao zastareo, kao nešto s čime je, ako je i imao susreta u svom detinjstvu, verovatno neće imati nikada više.

Na sličan način, reference na popularnu kulturu devedesetih godina prošlog veka asocijativno su povezane (posebno u kontekstu introspektivnog i subjektivnog, uspostavljenom putem zvučnih elemenata) s periodom detinjstva i rane adolescencije, odnosno, periodom izloženosti tim sadržajima. Ovde se posebno mogu izdvojiti reference na crtanu TV seriju „Simpsonov” koja je svakako najzastupljenija u kontekstu vaporwave-a i koja ujedno predstavlja gotovo jedini televizijski materijal koji se koristi s takvom učestalošću. Druge reference na popularnu kulturu istog perioda tiču se, $u$ prvom redu, video igara, i samo ređe drugih računarskih programa iz tog perioda. S tim na umu, nije teško zaključiti 
da vaporwave svoju simulaciju prošlosti dodatno oblikuje predstavljajući je ne samo kao prošlost, već kao ličnu prošlost, potencirajući, ne sadržaje koji su bili široko popularni tokom poslednje decenije dvadesetog veka, već one sadržaje koji su bili široko popularni među adolescentima.

Ukoliko je ova tvrdnja opravdana, onda reference na popularnu kulturu devedesetih godina prošlog veka, ali i na zastarelu tehnologiju, imaju jednu posebno značajnu deljenu karakteristiku - i jedni i drugi, onda kada su ,istrgnuti” iz svog originalnog istorijskog i kulturnog konteksta, i kada su smešteni u opoziciju sa sadašnjim trenutkom, postaju veoma moćni simboli koji mogu komunicirati izraženu tenziju između nekad i sad, uz jasan akcenat na neumitost protoka vremena.

Ali, potrebno je obratiti pažnju na još jedan veoma značajan segment prepoznatljivog izraza vaporwave-a, a koji odgovara onome što sam prethodno označio kao ,pravila oneobičavanja”. S jedne strane možemo pomenuti sve one elemente koji odgovaraju „kao da” pristupu, odnosno, one elemente koji su tu primarno da bi emulirali nešto, u konkretnom slučaju tehnička ograničenja iz prošlosti, ali isto tako i prošle vizije stila, estetike ili dizajna. $\mathrm{S}$ druge strane nalaze se elementi koji „simuliraju” nešto, koji različitim tehnikama simuliraju istoričnost jednog savremenog izraza. Ove tehnike uključuju u prvom redu specifičan kolorit, te šire shvaćen ,stil” slikovnih ostvarenja, sve ono što nije „istrgnuto" iz drugog, poznatog konteksta.

Ipak, čini se da su i tehnike emulacije i tehnike simulacije nešto što je $v a$ porwave pozajmio od svojih neposrednih preteča. Zapravo, kada zamenimo fascinaciju nesavršenošću analogne fotografije, svojstvenu chillwave-u, fascinacijom nesavršenostima (i ,stilskim promašajima”) rane digitalne umetnosti svojstvenom vaporwave-u, razlike između ,pravila oneobičavanja” u ova dva žanra čine se gotovo isključivo pitanjem forme. Takođe, slično chillwave-u, i vaporwave je obeležen dominacijom ružičasto-crvenih i tirkizno-zelenih tonova, ali, za razliku od chillwave-a, vaporwave umesto izbledelih i pastelnih tonova često nudi neonske, gotovo agresivne nijanse. Kako bismo mogli da protumačimo značenjski, a samim tim i afektivni potencijal upotrebe određenog kolorita, predložio bih da se, slično pristupu zvučnim elementima, okrenemo ka njihovoj istoričnosti.

Govoreći o pitanju konstrukcije nostalgije u digitalnim medijima, pomenuo sam pojavu hardverskih i softverskih tehnika emulacije različitih svojstava analogne fotografije. Težnja za oponašanjem ,toplih boja Polaroida” i česte nesavršenosti analogne fotografije, kao što su preduge ekspozicije, rezultira upravo takvom ,estetikom” koja je karakteristična za chillwave - izbledelim, pastelnim bojama koje se nalaze na spektru između ružičasto-crvenih i tirkizno-zelenih tonova (Bartholeyns 2014, 52). Ali, isti ovi metodi obrade fotografije dospeli su u širu javnost kroz filtere ponuđene na popularnim društvenim mrežama namenjenim deljenju fotografija, gde se koriste za postizanje „retro efekta” (Angé 
and Berliner 2016). Upravo na ovaj način uspostavljena je kulturna konvencija koja određen kolorit dovodi u asocijativnu vezu s prošlošću i na taj način kolorit, karakterističan za chillwave, uspešno oblikuje dati izraz tako da se on doživljava kao „retro”.

Ali, vaporwave odlazi korak dalje. U tom žanru, retro je „digitalni retro”, a ne ,analogni retro", što neonske boje u istom opsegu nijansi smešta ne samo u opoziciju s ,izbledelim” koloritom, koji je u sistemu značenja popularne kulture povezan s analognom fotografijom i snimkom, već i sa svedenim, minimalističkim dizajnom savremenog perioda. Neonska upadljivost kolorita vaporwave-a, kič i ,prenatrpanost” elementima predstavljaju ključne karakteristike njegovog izraza koje mu omogućavaju da zadrži jasnu distinkciju, ne samo u odnosu na sve druge „retro pokrete” s kojima deli pozornicu popularne kulture, već i u odnosu na „estetiku” savremenog trenutka.

\section{Završna razmatranja}

Kako nam dosadašnje izlaganje može pomoći da pokušamo da damo odgovore na centralna pitanja postavljena na početku ovog teksta? Počevši od kulturnog znanja na kom se zasniva kompetencija za učešće u ovim formama kulturne komunikacije, možemo reći da se, na najopštijem nivou, radi o poznavanju popularne kulture, odnosno, o njenim konvencijama i stilovima - ovo važi kako za zvučne, tako i za slikovne elemente svojstvene vaporwave-u. Neki primeri kompetencije, koja se na tom znanju zasniva, uključuju sposobnost da se muzička osnova numere prepozna s obzirom na vreme u kom je prvobitno nastala, poznavanje specifičnog afektivnog seta koji je povezan s reverberacijom, kao i poznavanje grafičkih i stilskih konvencija povezanih s „retro estetikom”. Drugim rečima, relevantno kulturno znanje uključuje poznavanje kulturnih i kognitivnih modela onih elemenata koji predstavljaju osnovu izraza vaporwave-a.

Ali, mnogi od ovih elemenata su ,istrgnuti” iz konteksta u kom ih inače srećemo i, kroz procese rekontekstualizacije, uključeni su u specifičan brikolaž. Počnimo od toga da poznavanje tih elemenata zapravo znači da kulturno znanje uključuje kulturne kognitivne modele, mentalne slike ovih elemenata koji su i sami kompleksni. Drugim rečima, naizgled ,prosti” elementi izraza vaporwa$v e$-a, nazovimo ih elementima prvog reda, i sami predstavljaju modele koji su prema shvatanjima Klaudije Štros i Naomi Kvin izgrađeni od međusobno povezanih i isprepletanih mreža elemenata (Strauss and Quinn 1997, 53-54), pri čemu su upravo te veze između elemenata drugog reda ono što nam omogućava interpretaciju elemenata prvog reda, te njihovo sagledavanje kao jedinstvenih fenomena. Prilikom rekontekstualizacije, ovi različiti kulturni modeli smeštaju se $u$ isti kontekst i dovode se u međusobnu vezu, a prilikom ostvarivanja tih relacija dolazi do izvesnih ,izmena” u unutrašnjoj strukturi modela. Rezultat tog 
procesa jeste veći značaj koji se pridaje nekim elementima drugog reda. Na taj način, recimo, TV serija „Simpsonovi” u kontekstu vaporwave-a gubi gotovo sva svoja druga tumačenja sem onih „temporalnih”, slično kao što razmatran osobeni kolorit ne može biti doživljen gotovo kao ništa više od puke reference na „retro”.

Drugim rečima, upravo ovaj proces rekontekstualizacije omogućava istim kulturnim kognitivnim modelima da se tumače i doživljavaju na donekle različite načine u različitim kontekstima, da igraju različite uloge u različitim značenjskim i logičkim odnosima s drugim modelima. Brikolaž vaporwave-a jeste brikolaž kulturnih elemenata koji se međusobno konstituišu u tom specifičnom kontekstu, usmeravajući tumačenje i lični doživljaj celine na takav način na koji ni jedan pojedinačni model ne bi mogao.

Svi ovi različiti elementi, onda kada su smešteni u zajednički kontekst žanra, postaju sintagmatski povezani, dakle, povezani po principu deo-celina (Lič 2002, 25), ali ta sintagmatska veza postoji samo onda kada kognitivni model vaporwave-a postoji u našem kulturnom znanju. Onog trenutka kada određeni ne-muzički elementi, ma kakva bila njihova priroda, postanu prepoznati kao povezani s nekim muzičkim žanrom, i kada ta veza postane deo kulturnog znanja, zvučni elementi sami mogu aktivirati kognitivni model žanra koji zauzvrat aktivira sve druge implicitno prisutne elemente, usmeravajući i standardizujući tumačenje, čak i onda kada se poruka čini ,nepotpunom”. Upravo zato možemo samo čuti vaporwave, a da naš lični doživljaj muzike bude upravo onakav kakav bi bio da su tu prisutni i svi drugi elementi, kao da je pred nama izraz karakteristične ,estetike" vaporwave-a. Iako su oni prisutni samo u našem sećanju, oni mogu aktivno uticati na naše tumačenje sadašnjosti, i upravo se tu nalazi odgovor na pitanje multimedijalnosti muzičkog žanra.

Značajno je napomenuti da u pogledu svog odnosa ka prošlosti vaporwave jeste prosto „muzička fikcija”. I istovetno književnoj fikciji, „kao da” pristup vaporwave-a ne tiče se prošlosti koliko sadašnjosti, on ne teži toliko da emulira prošlost, koliko da emulira naš subjektivni doživljaj prošlosti koja se možda nikada nije ni dogodila. Stoga, vaporwave teži da zapravo simulira istoričnost izraza koji tu istoričnost nema. Ali, to ne znači da vaporwave ne govori nešto o prošlosti, ili barem njenom društvenom i kulturnom shvatanju. Određujući se ka ovom pitanju, možemo se poslužiti tekstom Dragane Antonijević koji se upravo bavi konceptima sećanja i zaborava. Autorka tu piše da pojedinci i društva na različite načine „stvaraju i koriste koncept vremena” kako bi se „odredili i osimislili u istoriji” (Antonijević 2009, 256). Pritom, „koncepti socijalno konstruisanog vremena mogu biti ciklični, linearni i liminalni (snoliki, epohalni)" (Antonijević 2009, 256). U tom kontekstu, sećanje ima „,normativnu funkciju” budući da „daje repere društvu i uporišta identiteta” unutar određenog koncepta vremena (Antonijević 2009). 
U tom smislu, čini se da muzička fikcija vaporwave-a jeste pre konstrukcija sećanja nego konstrukcija prošlosti, i to takva koja se oslanja na „liminalni” koncept vremena koje niti prati neki linearni niz, niti teži da ponovo dođe. Naprotiv, vaporwave konstruiše sećanje na prošlost koja predstavlja jednu zbrku elemenata, čak i hronološki razdvojenih ali iskustveno, afektivno i značenjski neodvojivo povezanih. S tim na umu, možemo reći i da je ideja o ,internet generaciji” kao „tvorcu vaporwave-a" možda ne toliko pogrešna koliko pogrešno postavljena - vaporwave teži da bude tvorac ,internet generacije”, da stvori sećanja na vreme koje nikada nije zaista postojalo i da u njemu pronađe uporište u globalnoj, digitalnoj, virtualnoj stvarnosti.

Konstruišući kolektivno sećanje na liminalnu prošlost zasnovanu na deljenim iskustvima i izloženosti određenim kulturnim objektima i formama, uz nostalgičan osvrt ka njima, vaporwave konstruiše i svoje slušaoce i svoje stvaraoce kao ljude, ili možda pre kao „decu” jednog perioda, jedne ere, kao „generaciju interneta". Na taj način, vaporwave funkcioniše, baš kao i svaki drugi muzički žanr, i kao proizvođač identiteta (Ristivojević 2013).

\section{Literatura}

Angé, Olivia and David Berliner. 2016. Introduction to Anthropology and Nostalgia. Anthropology as Nostalgia. eds. Olivia Angé and David Berliner, 1-15. New York: Berghahn Books.

Antonijević, Dragana. 2009. „Povodom Levi-Strosovog koncepta 'motiva zaborava'. Struktura poremećene komunikacije i stilovi mišljenja u tranzicijskoj Srbiji”. U Strukturalna antropologija danas: tematski zbornik u čast Kloda Levi-Strosa, ur. Dragana Antonijević, 244-295. Beograd: Srpski genealoški centar i Odeljenje za etnologiju i antropologiju Filozofskog fakulteta.

Bakardjieva, Maria. 2005. Internet Society: The Internet in Everyday Life. Lodnon: Sage Publications.

Bartholeyns, Gil. 2014. ,The Instant Past: Nostalgia and Digital Retro Photography”. In Media and Nostalgia, Katharina Niemeyer ed., 51-69. Basingstoke: Palgrave Macmillan.

Becker, Judith. 2004. Deep Listeners: Music, Emotion and Trancing. Indianapolis: Indiana University Press.

Berger, Harris M. 2009. Stance: Ideas about Emotion, Style, and Meaning for the Study of Expressive Culture. Middletown: Wesleyan University Press.

Budd, Malcolm. 1992. Music and Emotions: The Philosophical Theories. London: Routledge.

Christensen, Justin. 2018. Sound and the Aesthetics of Play: A Musical Onthology of Constructed Emotions. Aalborg: Palgrave Macmillan.

Coleman, Gabriella. 2010. Ethnographic Approaches to Digital Media. Annual Review of Anthropology 39 (1): 487-509.

Csordas, Thomas J. 1990. Embodiment as a Paradigm for Anthropology. Ethos 18 (1): 5-47. de Munck, Victor C. 2013. A Theory Explaining the Functional Linkage between the Self, Identity and Cultural Models. Journal of Cognition and Culture 13 (1): 179-200. 
Finnegan, Ruth. 2003. „Music, Experience and Anthropology of Emotions”. In The Cultural Study of Music: A Critical Introduction, eds. Martin Clayton, Trevor Herbert and Richard Middleton, 185-196. London: Routledge.

Fisher, Mark. 2014. Ghosts of my Life: Writings on Depression, Hauntology and Lost Futures. Winchester: Zero Books.

Gerc, Kliford. 1998. Tumačenje kultura. Beograd: XX vek.

Leavitt, John. 1996. Meaning and Feeling in the Anthropology of Emotions. American Ethnologist 23 (3): 514-539

Levi-Stros, Klod. 2009. Mit i značenje. Beograd: Službeni glasnik.

Lič, Edmund. 2002. Kultura i komunikacija. Beograd: XX vek.

Lysloff, Rene T. A. 2003. „Musical Life in Softcity: An Internet Etnography”. In Music and Technoculture, eds. R. Lysloff i L. Gay, 23-63. Middletown: Wesleyan University Press.

Merriam, Allan P. 1964. The Anthropology of Music. Evanston: Northwestern University Press.

Niemeyer, Katharina. 2014. Introduction to Media and Nostalgia. In Media and Nostalgia, ed. Katharina Niemeyer, 11-23. Basingstoke: Palgrave Macmillan.

Oltețeanu, Ion. 2010. Understanding Music Theory: Meaning, Self-Consciousness, and Emotional Expressiveness. New York: Addleton Academic Publishers.

Ože, Mark. 2005. Nemesta. Beograd: XX vek.

Perlman, Marc. 2003. „Consuming Audio: An Introduction to Tweak Theory”. In Music and Technoculture, eds. R. Lysloff i L. Gay, 346-357. Middletown: Wesleyan University Press.

Pickering, Michael and Emily Keightley. 2006. The Modalities of Nostalgia. Current Sociology 54: 919-41.

Robinson, Jenefer. 2005. Deeper than Reason: Emotion and its Role in Literature, Music and Art. Oxford: Clarendon Press.

Ristivojević, Marija. 2012. Proučavanje muzike u antropologiji. Etnoantropološki problemi 7 (2): 471-486.

Ristivojević, Marija. 2013. Muzika kao kulturni fenomen. Etnoantropološki problemi 8 (2): 441-451.

Schrey, Dominik. 2014. „Analogue Nostalgia and the Aesthetics of Digital Remediation". In Media and Nostalgia, ed. Katharina Niemeyer, 27-38. Basingstoke: Palgrave Macmillan. Spracklen, Karl. 2015. Digital Leisure: The Internet and the Popular Culture. Basingstoke: Palgrave Macmillan.

Strauss, Claudia and Quinn, Naomi. 1997. A Cognitive Theory of Cultural Meaning. Cambridge: Cambridge University Press.

Tarner, Viktor. 1989. Od rituala do teatra: ozbiljnost ljudske igre. Zagreb: August Cesarec. Žakula, Sonja. 2012. Da li kiborzi sanjaju biomehaničke ovce? Telo i hiperrealnosti. Antropologija 12 (2): 43-61.

Žikić, Bojan. 2009. „Za šta su dobri žanrovi? Deljenje, razgraničavanje i razvrstavanje u strukturalnoj i kognitivnoj antropologiji na primeru muzičke kulture". U Strukturalna antropologija danas: tematski zbornik u čast Kloda Levi-Strosa, ur. Dragana Antonijević, 326-361. Beograd: Srpski genealoški centar i Odeljenje za etnologiju i antropologiju Filozofskog fakulteta. 
Žikić, Bojan. 2010. Antropologija i žanr: naučna fantastika - komunikacija identiteta, Etnoantropološki problemi 5 (1): 17-34.

Žikić, Bojan. 2012. Popularna kultura, nadkulturna komunikacija, Etnoantropološki problemi 7 (2): 315-341.

Igor Vujčić

$\mathrm{PhD}$ candidate, Department of Ethnology and Anthropoly

Faculty of Philosophy, University of Belgrade, Serbia

\section{Digital nostalgia: Vaporwave as a multimedia musical fiction}

Vaporwave as a musical genre with a limited number of mostly anonymous performers, but also with a very limited duration of only a few years, is inseparably linked to the phenomenon of the Internet that functions not only as a place where musicians and their audience meet, but as the primary cultural framework of this genre. Relying on the techniques of processing already existing musical expressions, as well as on visual representations and references to the popular culture of nineties, marked in the context of the genre as ,aesthetics”, vaporwave tends to show and awake with his listeners nostalgia during the early beginnings of the Internet, shaping his expression, both musical and visual, with the goal of acting ,as if" comes from another time. The phenomenon of vaporwave will be addressed through several central and interrelated questions - how techniques of sound processing, visual representations and elements of popular culture are brought into interconnection within the musical genre contributing to its multimedia nature, how these elements are separated from their primary interpretations in the processes of retextualization and the creation of a specific bricolage, and on which cultural knowledge the competence for participation in such forms of cultural communication is based.

Key words: vaporwave, music culture, cultural communication, popular culture, meaning and emotion

Nostalgie numérique: vaporwave comme fiction musicale multimédiatique

Le vaporwave comme genre musical avec un nombre limité d'exécutants majoritairement anonymes, mais aussi avec une existence très limitée de quelques années seulement, est indissociablement lié au phénomène de l'internet qui fonctionne non seulement comme un espace dans lequel se rencontrent les musiciens et leur public mais aussi comme un cadre culturel primaire de ce genre musical. En s'appuyant sur les techniques de montage des formes musi- 
cales déjà existantes, ainsi que sur des représentations visuelles et des références à la culture populaire des années quatre-vingt-dix du siècle passé, marquées dans le contexte du genre comme « esthétique», vaporwave tend à exprimer et à éveiller chez ses auditeurs la nostalgie du temps des premiers débuts de l'internet, modelant son expression, aussi bien musicale que visuelle, avec l'objectif de produire l'effet « comme si » elle venait d'un autre temps. Le phénomène du vaporwave sera examiné à travers quelques questions centrales et mutuellement reliées - la manière dont les techniques de montage du son, les représentations visuelles et les éléments de la culture populaire sont mis en rapport les uns avec les autres dans le cadre de ce genre musical contribuant à sa nature multimédiatique, comment ces éléments se séparent de leurs interprétations primaires dans des processus de recontextualisation et de la création d'un bricolage particulier, et sur quel savoir culturel est fondée la compétence pour la participation dans de telles formes de communication culturelle.

Mots clés: Vaporwave, culture musicale, communication culturelle, culture populaire, signification et émotion

Primljeno / Received: 14.05.2018.

Prihvaćeno / Accepted: 29.10.2018. 